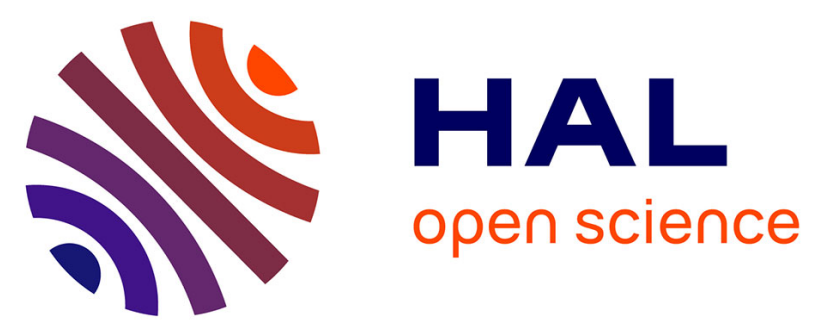

\title{
A TILLING allele of the tomato Aux/IAA9 gene offers new insights into fruit set mechanisms and perspectives for breeding seedless tomatoes
}

Andrea Mazzucato, Francesco Cellini, Mondher Bouzayen, Mohamed Zouine, Isabelle Mila, Silvia Minoia, Angelo Petrozza, Maurizio E. Picarella, Fabrizio Ruiu, Filomena Carriero

\section{To cite this version:}

Andrea Mazzucato, Francesco Cellini, Mondher Bouzayen, Mohamed Zouine, Isabelle Mila, et al.. A TILLING allele of the tomato Aux/IAA9 gene offers new insights into fruit set mechanisms and perspectives for breeding seedless tomatoes. Molecular Breeding, 2015, vol. 35 ( $\mathrm{n}^{\circ} 1$ ), pp. 1-15. 10.1007/s11032-015-0222-8 . hal-01223244

\section{HAL Id: hal-01223244 \\ https://hal.science/hal-01223244}

Submitted on 2 Nov 2015

HAL is a multi-disciplinary open access archive for the deposit and dissemination of scientific research documents, whether they are published or not. The documents may come from teaching and research institutions in France or abroad, or from public or private research centers.
L'archive ouverte pluridisciplinaire HAL, est destinée au dépôt et à la diffusion de documents scientifiques de niveau recherche, publiés ou non, émanant des établissements d'enseignement et de recherche français ou étrangers, des laboratoires publics ou privés. 


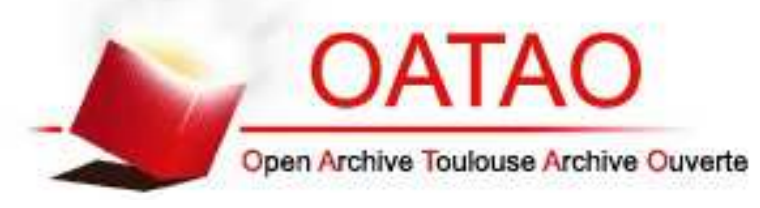

\section{Open Archive TOULOUSE Archive Ouverte (OATAO)}

OATAO is an open access repository that collects the work of Toulouse researchers and makes it freely available over the web where possible.

This is an author-deposited version published in : http://oatao.univ-toulouse.fr/ Eprints ID : 14423

To link to this article : doi: $10.1007 / \mathrm{s} 11032-015-0222-8$

URL : http://dx.doi.org/10.1007/s11032-015-0222-8

To cite this version : Mazzucato, Andrea and Cellini, Francesco and Bouzayen, Mondher and Zouine, Mohamed and Mila, Isabelle and Minoia, Silvia and Petrozza, Angelo and Picarella, Maurizio E. and Ruiu, Fabrizio and Carriero, Filomena A TILLING allele of the tomato Aux/IAA9 gene offers new insights into fruit set mechanisms and perspectives for breeding seedless tomatoes. (2015) Molecular Breeding, vol. 35 ( ${ }^{\circ}$ 1). ISSN 1380-3743

Any correspondance concerning this service should be sent to the repository administrator: staff-oatao@ listes-diff.inp-toulouse.fr 


\title{
A TILLING allele of the tomato Aux/IAA9 gene offers new insights into fruit set mechanisms and perspectives for breeding seedless tomatoes
}

\author{
Andrea Mazzucato - Francesco Cellini - Mondher Bouzayen - Mohamed Zouine • \\ Isabelle Mila $\cdot$ Silvia Minoia $\cdot$ Angelo Petrozza $\cdot$ Maurizio E. Picarella • \\ Fabrizio Ruiu · Filomena Carriero
}

\begin{abstract}
Parthenocarpy is a desired trait in fruit crops; it enables fruit set under environmental conditions suboptimal for pollination, and seedless fruits represent a valuable consumer product. We employed TILLING-based screening of a mutant tomato population to find genetic lesions in $A u x / I A A 9$, a negative regulator of the auxin response involved in the control of fruit set. We identified three mutations located in the coding region of this gene, including two singlebase substitutions and one single-base deletion, which
\end{abstract}

Electronic supplementary material The online version of this article (doi:10.1007/s11032-015-0222-8) contains supplementary material, which is available to authorized users.

\section{A. Mazzucato · M. E. Picarella $\cdot$ F. Ruiu} Department of Science and Technologies for Agriculture, Forestry, Nature and Energy (DAFNE), University of Tuscia, Via S.C. de Lellis snc, 01100 Viterbo, Italy e-mail: mazz@unitus.it

M. E. Picarella

e-mail: picarella@unitus.it

F. Ruiu

e-mail: fabrizioruiu@yahoo.it

F. Cellini $\cdot$ S. Minoia $\cdot$ A. Petrozza $\cdot$ F. Carriero $(\bowtie)$

ALSIA-Centro Ricerche Metapontum Agrobios, SS

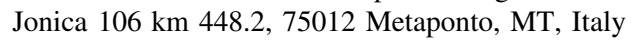

e-mail: fcarriero@agrobios.it; filomena.carriero@alsia.it

F. Cellini

e-mail: francesco.cellini@alsia.it

S. Minoia

e-mail: sminoia@hotmail.com leads to a frame shift and premature stop codon. The transcription of IAA9 was strongly reduced in the frame-shift mutant, and partial loss of mutated protein activity was evidenced by an in vitro transactivation assay. Whereas missense mutations were predicted to be tolerated and did not cause mutant phenotypes, the frame-shift mutation-induced phenotypes expected for a loss of IAA9 function, including altered axillary shoot growth, reduced leaf compoundness and a strong tendency to produce parthenocarpic fruits. Mutant flowers showed pleiotropic anther cone defects, a phenotype frequently associated with parthenocarpy in tomato and other species. Mutant fruits were larger than those of the seeded control, with higher brix

\section{A. Petrozza \\ e-mail: angelo.petrozza@alsia.it}

\section{Bouzayen · M. Zouine · I. Mila}

INP-ENSAT, Laboratory of Genomics and Biotechnology of Fruit, University of Toulouse, Avenue de l'Agrobiopole BP 32607, Castanet-Tolosan 31326, France

e-mail: bouzayen@ensat.fr

M. Zouine

e-mail: mohamed.zouine@ensat.fr

I. Mila

e-mail: mila@ensat.fr

M. Bouzayen · M. Zouine · I. Mila

INRA, UMR990 Génomique et Biotechnologie des Fruits, Chemin de Borde Rouge, Castanet-Tolosan 31326, France 
values and similar firmness. Fruit set was higher in the mutant than in wild type in the greenhouse, but lower in the open field. Facultative expression of parthenocarpy indicated that the mutant is suitable for hybrid seed production and for increasing seeds of parental lines. The results highlight the utility of this novel IAA9 allele for exploiting parthenocarpy by breeding tomato adapted to pollination-limiting growth conditions.

Keywords Aux/IAA transcription factors · Fruit set · Parthenocarpy $\cdot$ Solanum lycopersicum .

TILLING $\cdot$ Tomato

\section{Introduction}

The parthenocarpic growth of the ovary into a seedless fruit without pollination and/or fertilisation is a very attractive trait for breeders and has been extensively studied in tomato, where natural or induced facultative parthenocarpic mutants are known to occur (Gorguet et al. 2005; Srivastava and Handa 2005). Notwithstanding the potential interest of these mutations, their adoption in tomato breeding has been hindered by the facultative expression, negative pleiotropic traits and lack of markers to accelerate selection schemes. The parthenocarpic fruit (pat) mutation, the first gene for parthenocarpy discovered in tomato (Bianchi and Soressi 1969), is characterised by a phenotype with high penetrance and expressivity that also entails earlier ripening and enhanced fruit quality (Falavigna et al. 1978). At maturity, the seedless pat fruits are typically smaller than seeded fruits produced by wildtype plants (Bianchi and Soressi 1969; Falavigna et al. 1978). Moreover, such a genotype presents floral defects that make the production of seeds difficult, even under conditions favourable for pollination (Mazzucato et al. 1998, 2003). The pat-2 mutant, an alternative parthenocarpic mutant non-allelic to pat, yields fruits of the same shape and weight as the corresponding wild-type fruits (Philouze et al. 1988). However, pat-2 is more facultative than pat (Lin et al. 1984). While facultativeness simplifies increasing seeds of parthenocarpic stocks, it hinders selection in breeding schemes. A lack of information about the map position of the Pat-2 locus has prevented the development of molecular markers for assisted selection. A third parthenocarpic system, pat-3/pat4 , presents the problem of polygenic inheritance as well as smaller fruits (Nuez et al. 1986). In addition, all of the described parthenocarpic genotypes exhibit reduced firmness of the seedless fruits (Philouze et al. 1988; Santangelo et al. 1990; Gorguet et al. 2005), which further limits the adoption of genetic parthenocarpy in tomato breeding.

The recent elucidation of the molecular genetic mechanisms controlling fruit set in tomato has paved the way for harnessing new mutations for parthenocarpy. The flower-to-fruit transition is under complex multihormonal regulation, and the molecular mechanisms underlying this process continue to be intensively investigated (reviewed by Ruan et al. 2012). The molecular characterisation of mutants (Fos et al. 2000, 2001; Olimpieri et al. 2007; Mazzucato et al. 2008) and extensive reverse genetic studies (Ampomah-Dwamena et al. 2002; Wang et al. 2005; Goetz et al. 2007; Martí et al. 2007; De Jong et al. 2009; Molesini et al. 2009; Ren et al. 2011) have indicated that a network of repressors is established in the ovary of a mature tomato flower to control its growth until fertilisation has taken place.

IAA9, a member of the Aux/IAA family of transcription factors (TFs) in tomato, plays a major role in fruit set, as plants silenced by antisense technology (AS-IAA9) show several IAA-related developmental defects, including strong parthenocarpic behaviour (Wang et al. 2005). AS-IAA9 plants exhibit a dramatic reduction in leaf compoundness, enhanced hypocotyl/stem elongation, increased leaf vascularisation and reduced apical dominance (Wang et al. 2005). At flowering, downregulation of IAA9 results in a precocious set prior to anthesis of seedless fruits, which are similar in appearance to wild-type tomato fruits in terms of size, skin colour and flesh consistency (Wang et al. 2005). RT-PCR and in situ hybridisation have shown that a tissue-specific gradient of IAA9 expression is established during flower development, the release of which, upon pollination and fertilisation, triggers the initiation of fruit development (Wang et al. 2009).

A single-base deletion of the IAA9 gene, resulting in a frame shift and a truncated protein, underlies the entire (e) tomato mutant, whose simple leaves phenocopy those of AS-IAA9 plants (Zhang et al. 2007). However, the reproductive phenotypes of this mutant have not been described. 
Studies in Arabidopsis have unravelled several insights into the structure and function of the Aux/IAA proteins. Aux/IAA are short-lived TFs that regulate downstream auxin responses (Guilfoyle 1998; Reed 2001). These proteins share four highly conserved domains: domain I contains a functionally characterised transcriptional repressor motif, domain II interacts with a component of the ubiquitin-proteasome protein degradation pathway that is essential for auxin signalling, and domains III and IV act as C-terminal dimerisation domains mediating homodimerisation and heterodimerisation among Aux/IAA family members, and dimerisation with similar domains found in Auxin Response Factor (ARF) proteins (Kim et al. 1997; Ulmasov et al. 1997). The presence of IAA promotes Aux/IAA protein ubiquitination and its degradation by the $26 \mathrm{~S}$ proteasome (Gray et al. 2001). ARFs are thus released from the repressive effect, and auxin response genes are finally activated (Dharmasiri et al. 2005; Tan et al. 2007).

In contrast to Arabidopsis, where loss-of-function mutations fail to provide clues to the physiological significance of Aux/IAA proteins likely due to functional redundancy (Overvoorde et al. 2005), downregulation of $A u x / I A A$ genes in tomato frequently results in strong and differentiated phenotypes (Wang et al. 2005; Chaabouni et al. 2009; Bassa et al. 2012; Deng et al. 2012). This has provided an efficient means for deciphering the specific roles of various members of the $A u x / I A A$ family, comprising 25 genes in this Solanaceae species (Audran-Delalande et al. 2012).

Recently, the Targeting-Induced Local Lesions IN Genomes (TILLING) strategy was developed to investigate the functions of specific genes and to provide a non-transgenic tool for improving domesticated crops by identifying novel genetic variations in genes that affect key traits (Slade et al. 2005). The screening of a TILLING resource in the tomato MicroTom genetic background yielded three IAA9 mutant alleles showing vegetative and reproductive phenotypes comparable to those of AS-IAA9 (Saito et al. 2011). Genotypes carrying these alleles show variable rates of parthenocarpic fruit development from emasculated flowers (Saito et al. 2011).

In the current study, to identify novel loss-offunction alleles affecting the IAA9 coding sequence, we performed screening using a TILLING platform developed in the genetic background of Red Setter, a processing cultivar with a determinate habit (Minoia et al. 2010). Due to their expected parthenocarpic phenotype, IAA9-mutated lines can be valuable for breeding seedless tomato varieties and for further elucidating the role of IAA9 in the machinery controlling fruit set.

\section{Materials and methods}

\section{TILLING screening}

To search for induced point mutations in the IAA9 gene, the Red Setter TILLING platform described by Minoia et al. (2010) was employed. Red Setter is a processing tomato variety with a determinate growing habit, which is suitable for mechanical harvesting, showing a very early and concentrated set of elongated fruits with remarkable firmness. The molecular analysis was based on nested-PCR and was carried out using two pairs of gene-specific primers designed based on the deposited sequence for IAA9 [GenBank: AJ937282 and Solyc04g076850]. These primers amplify the first four exons including the first three conserved domains (Fig. S1). In the first PCR, $4 \mathrm{ng}$ of eightfold pooled genomic DNA was used as a substrate for amplification with the external primers 5'-TGGGTCTATCTGATTGTTCGTC-3' (F1, forward) and 5'-GAGCAGAAGATAGCTCCTGGTA TG-3' (R1, reverse). Subsequently, $1 \mu$ l of the first PCR reaction served as a template for the second amplification using the internal primers $5^{\prime}$-TCCAC CTCATCAGAGGACAA-3' (F2, forward) and $5^{\prime}$ TCAAATAGGGAGCACCATCC-3' (R2, reverse). The internal primers were $5^{\prime}$-end labelled with IRDye 700 and IRDye 800 dye (LI-COR ${ }^{\circledR}$, Lincoln, NE, USA), respectively. The PCR amplifications were carried out according to the experimental conditions described in Dalmais et al. (2008).

Mutation detection was performed with the mismatch-specific endonuclease ENDO I (Triques et al. 2007) and a LI-COR 4300 DNA analyser (LI-COR ${ }^{\circledR}$ ). Gel images were analysed using Adobe Photoshop software (Adobe Systems Inc., San José, CA, USA). After discovery, mutations were validated by Sanger sequencing. Sequence alignment was performed using the ClustalW (version 1.82) multiple sequence alignment program (Thompson et al. 1994). SIFT software ( $\mathrm{Ng}$ and Henikoff 2003) was used to predict the effect of amino acid changes on protein activity. 
Genotyping of mutant plants

$\mathrm{M}_{3}$ seeds of the families containing mutations were recovered, and $15 \mathrm{M}_{3}$ plants per family were grown in a greenhouse and genotyped by Sanger sequence analysis. Plants homozygous for the mutations C274T and $\mathrm{C} 512 \mathrm{~T}$ and for the single-base deletion T618 (hereafter referred to as $\mathrm{T} 618^{*}$ ) were identified and used in a first backcross to Red Setter (hereafter referred to as WT). $\mathrm{BC}_{1} \mathrm{~F}_{1}$ plants were selfed, and $\mathrm{BC}_{1} \mathrm{~F}_{2}$ progenies were genotyped for the respective mutations as described below. From homozygous $\mathrm{BC}_{1} \mathrm{~F}_{2}$ mutant plants, a further selfing was adopted to obtain $\mathrm{BC}_{1} \mathrm{~F}_{3}$ seed stocks fixed for the mutations (hereafter referred to as iaa9-274, iaa9-512 and iaa9618 mutant lines for the C274T, C512T and T618* alleles, respectively).

To genotype the C274T and C512T mutations, codominant cleaved amplified polymorphic sequence (CAPS) markers were developed. Genomic DNA extracted according to Doyle and Doyle (1987) was PCR-amplified using the external primers employed for the TILLING screening, and the 820-bp-long PCR fragment was digested with BplI and RsaI for the assessment of each mutation, respectively. The homozygous allelic condition of the C274T mutation was revealed by the presence of two BpII-digested DNA bands (687 and $133 \mathrm{bp}$ ), while the WT allele showed the uncut DNA band. For the C512T mutation, the 587 and 233 bp RsaI digestion products enabled plants homozygous for the mutation to be distinguished from the WT allelic condition, which presented three digested DNA bands (464, 233 and 123 bp). Progeny segregating T618* were genotyped by sequencing.

\section{Real-time PCR}

Young leaves from 30-day-old WT plants and $\mathrm{BC}_{1} \mathrm{~F}_{2}$ plants homozygous for the three mutations were collected and quick-frozen in liquid nitrogen. From the $\mathrm{BC}_{1} \mathrm{~F}_{2}$ population segregating $\mathrm{T} 618^{*}$, heterozygous and wild-type sibling plants were also sampled. In addition, IAA9 expression analysis was performed using ovaries dissected from WT and iaa9-618 flowers $2 \mathrm{~d}$ before and $2 \mathrm{~d}$ after anthesis. Plant tissues were ground to a powder with a mortar and pestle, and total RNA was extracted using TRIzol reagent (Invitrogen, Carlsbad, CA, USA) according to the manufacturer's protocol. The yield and purity of the RNA samples were assessed by spectrophotometry, and RNA integrity was confirmed by $1 \%$ (w/v) agarose gel electrophoresis.

Next, cDNA was synthesised from $3 \mu \mathrm{g}$ of three independent RNA preparations using ThermoScript RNase H- Reverse Transcriptase (Invitrogen, Carlsbad, CA, USA) following the manufacturer's protocol. Tenfold dilutions of first-strand cDNA were used for real-time PCR (qRT-PCR) amplification experiments. Duplicate quantitative assays for each sample were performed with a SensiMix Capillary Kit (Bioline, Luckenwalde, Germany) in a LightCycler 2.0 system (Roche Applied Science) according to the manufacturer's instructions. Primers used to analyse the expression of IAA9 were 5'-TAGATGCTTTACCTGATTACGACA- $3^{\prime}$ (forward) and 5'-TGCAGACAA ACTCCAATATCAAAC- $3^{\prime}$ (reverse). Reactions were performed via an initial incubation at $95{ }^{\circ} \mathrm{C}$ for $10 \mathrm{~min}$ followed by $95{ }^{\circ} \mathrm{C}$ for $15 \mathrm{~s}, 60{ }^{\circ} \mathrm{C}$ for $15 \mathrm{~s}$ and $72{ }^{\circ} \mathrm{C}$ for $15 \mathrm{~s}$ for 40 cycles. Relative expression was calculated with the comparative $\mathrm{Ct}$ method using CAC (Solyc08g006960) as a housekeeping gene (Expósito-Rodríguez et al. 2008). Relative expression data were reported as the percentage of the value estimated in the WT control.

Transactivation assay between DR5 auxin response promoter and proteins encoded by three IAA9 mutant alleles

Total RNA was extracted with a Totally RNA ${ }^{\mathrm{TM}}$ Kit (Ambion, Inc., TX, USA) from leaf tissue of plants homozygous for the C274T, C512T and T618* mutations, and an aliquot was reverse transcribed with oligo $(\mathrm{dT})_{20}$ using a ThermoScript ${ }^{\mathrm{TM}}$ RT-PCR System (Invitrogen, Carlsbad, CA).

The cDNA was solubilised in $18 \mu \mathrm{l}$ of water, and a PCR was run on the cDNA with primers $5^{\prime}$-ATGTCTC CGCCGCTCCTTGGTGTTG-3' (forward) and 5'-GC TGGATGGATAGCTTTAATCA-3' (reverse) using high-fidelity polymerase (Phusion, Finnzymes, Helsinki, Finland) to amplify the complete cds. Then, the PCR products were cloned into the pGMNT vector (Promega, Wisconsin, USA), and the sequences were checked by sequencing. A second PCR was performed on two positive pGMNT clones for each cDNA, and the PCR product was transferred to a pEntry vector (pDonor207, Gateway, Invitrogen) and an expression vector (pEarleyGate 201). 
The ability of the IAA9 mutant proteins to in vivo regulate the activity of the synthetic DR5 auxinresponsive promoter fused to the GFP reporter gene (Ottenschlager et al. 2003) was investigated by transient expression experiments using BY-2 protoplasts (Audran-Delalande et al. 2012). The DR5::GFP construct acts as an auxin response reporting element containing AuxREs, which indirectly reflects the auxin response (Ulmasov et al. 1997).

Protoplasts for transfection were obtained from suspension-cultured tobacco (Nicotiana tabacum) BY2 cells according to a previously described method (Leclercq et al. 2005). Protoplasts were transfected by a modified polyethylene glycol method as described (Abel and Theologis 1994). For co-transfection assays, aliquots of protoplasts $\left(0.2 \times 10^{6}\right)$ were transformed with either $10 \mu \mathrm{g}$ of the reporter vector alone (containing the DR5 promoter fused to the GFP reporter gene) or in combination with $10 \mu \mathrm{g}$ of the IAA9 mutant constructs as the effector plasmid. A control with the DR5 promoter co-transformed with the WT IAA9 construct was also performed. Then, the protoplasts were treated (or not) with auxin $(50 \mu \mathrm{M} 2,4-\mathrm{D})$. Transformation assays were performed in three independent replicates. After 16 h, GFP expression was analysed and quantified by flow cytometry (FACS Calibur II instrument, BD Biosciences, San Jose, CA). For each sample, between 1,000 and 3,000 protoplasts were gated on forward light scatter. The GFP fluorescence per population of cells corresponded to the average fluorescence intensity of the population of cells above the background threshold (set arbitrarily based on a zero DNA transformed control). Data were analysed using Cell Quest software (BD Biosciences, Palo Alto, CA). The activity of the DR5 promoter was measured in the presence of the empty vector as a control (pEarleyGate), the IAA9-WT or the three IAA9 mutant alleles.

Phenotyping of the iaa9-618 mutant plants

Data on vegetative and reproductive phenotypes were obtained from $\mathrm{BC}_{1} \mathrm{~F}_{3}$ plants of the iaa9-618 line compared with plants of the WT control.

A trial with $\mathrm{BC}_{1} \mathrm{~F}_{3}$ plants in a protected environment was carried out in a tunnel-shaped, ventilated greenhouse under ambient light conditions in Viterbo $\left(42^{\circ} 26^{\prime} \mathrm{N}, 12^{\circ} 04^{\prime} \mathrm{E}\right)$, Italy, in late spring-summer. During the flowering period (month of May), the mean maximum temperature was $29.3^{\circ} \mathrm{C}$ and the mean minimum temperature was $12.2^{\circ} \mathrm{C}$, while the mean natural photoperiod was $14.5 \mathrm{~h}$. Twenty-four plantlets per genotype (divided in two replicates) were planted in soil and grown under standard cultural practices.

The number of seedling showing aberrations in cotyledon phenotype was counted and reported as the percentage over the total number of seedlings. On a single plant basis, leaf compoundness (number of simple and compound leaflets of the fourth leaf) and apical dominance (length of the axillary shoot at the second, fourth and last node before the first inflorescence at the time the second inflorescence was opening) were measured.

The time to flowering was estimated by counting the number of leaves produced before the first inflorescence. On the second inflorescence, the type of inflorescence (simple, double or multiple) was scored and the number of flowers counted. A total of 24 flowers, harvested at anthesis from the second inflorescence of each plant, were used to examine the morphology of floral organs, to count their number and to weigh the ovaries. A second flower from the same inflorescence was emasculated $2 \mathrm{~d}$ before anthesis and kept unpollinated. The weight of ovaries/fruitlets from unpollinated flowers was measured after $15 \mathrm{~d}$.

The fertility of iaa9-618 mutant plants was assessed by counting the seeds produced in controlled crosses. Ovule viability was estimated using the mutant as the seed parent and WT plants as pollen donors. Conversely, pollen fertility was estimated by pollinating WT flowers with pollen collected from the iaa9-618 line.

At maturity, the productive performance was estimated by observing the percentage of fruit set on the first four trusses (taking into account that two flowers from the second truss had been detached for earlier analysis). On the red ripe fruits harvested, the fruit weight, polar diameter and equatorial diameter were measured. Fruits were bulked on a single plant basis yielding 24 data points involving a total of about 120 fruits per genotype. The fruit shape index was calculated as the ratio between polar and equatorial diameter. The potential yield of the first four trusses was calculated considering the total number of fruits (red and green) multiplied by the mean weight of red ripe fruits.

The first two fruits that ripened on each plant were cut, and the soluble solids content (brix) was measured 
in the juice obtained after extracting the seeds using a digital refractometer (MA871, Milwaukee, Milwaukee Instruments, Inc., NC, USA) on a single fruit basis. The number of seeds was also counted on a single fruit basis. For the remaining fruits, brix values were measured in the juice extracted in bulk, bulked seeds were counted and the unitary number of seeds per fruit was calculated. Fruit firmness was measured on a representative red ripe fruit per plant with an Instron Universal Testing Machine (Instron Ltd., High Wycombe, UK) at $10 \mathrm{~N}$ and $25 \mathrm{~m} / \mathrm{s}$ of speed. On the iaa9618 line, trusses of orders higher than four were also harvested to extract the seeds.

The open-field trial was set up with $\mathrm{BC}_{1} \mathrm{~F}_{3}$ plants in the summer in Lavello $\left(41^{\circ} 03^{\prime} \mathrm{N}, 15^{\circ} 48^{\prime} \mathrm{E}\right.$; Potenza province), Italy, a location and growing season particularly favourable for processing tomato. During the flowering period (15th June-15th July), the mean maximum temperature was $30.2^{\circ} \mathrm{C}$ and the mean minimum temperature was $16.5^{\circ} \mathrm{C}$, while the mean natural photoperiod was $15.0 \mathrm{~h}$. A randomised block design with three replicates and 30 plants per replicate for the WT and iaa9-618 line, respectively, was adopted. At maturity, the five best performing plants per replicate were sampled, and on a single plant basis, red ripe fruits were harvested and counted together with green and rotten fruits. Using ten representative fruits per replicate, the productive and qualitative traits were measured (fruit weight, fruit diameters, number of seeds, brix and firmness) or calculated (shape index) as described above. The potential yield was calculated considering the total number of fruits (red, green and rotten) multiplied by the mean weight of red ripe fruits.

\section{Statistical analysis}

The significance of differences in expression data and DR5 promoter activity was tested on raw data by analysis of variance adopting the General Linear Model (GLM) using SAS software (SAS 2004). Data were graphically reported as a percentage of the value detected in the WT or under control conditions. Significance between mean values was estimated by Tukey's HSD test carried out on raw data. The significance of differences between genotypes for all other phenotypic traits was assessed by Student's $t$ test using Microsoft Excel. However, to compare estimates made as percentages, homogeneity $\chi^{2}$ analysis was adopted, where expected values were determined on the basis of totals in lines and columns in a $2 \times 2$ table. The regression between fruit weight and number of seeds was calculated for WT and iaa9618 fruits by SAS (PROC REG).

\section{Results}

Identification of new allelic variants of the IAA9 gene

To identify novel mutations in the IAA9 coding sequence, we employed TILLING as a reverse genetic approach (McCallum et al. 2000) using the ethyl methane sulphonate (EMS) mutant collection generated in the genetic background of the processing tomato cultivar Red Setter (Minoia et al. 2010). Specific primers were designed based on the IAA9 cDNA sequence to amplify the first four exons of the gene including the first three conserved domains (Fig. S1).

The screening of 5,200 $\mathrm{M}_{3}$ families allowed the identification of three mutations located in the IAA9 coding region. Two mutations, C274T and C512T, consisted of a single-base substitution (transition) while the third, T618*, was a single-base deletion. At the protein level, C274T and C512T caused amino acid changes leading to the substitution of proline with serine at position 92 (P92S) and threonine with isoleucine at position 171 (T171I), respectively (Fig. 1). The deletion of thymine at position 618 of the IAA9 coding region led to a frame shift and the formation of a premature stop codon, generating a predicted truncated protein of 210 amino acids in comparison with the 349 residues of the WT protein. The first 205 amino acids of the truncated and WT IAA9 proteins were identical, while the frame shift caused five amino acid substitutions (Fig. 1).

By considering the position of the mutations with reference to the four functional domains of the IAA9 protein, the P92S and T171I amino acid substitutions fell within the protein region between domain I and II (Fig. 1). These substitutions were both considered to be functionally tolerated according to SIFT analysis (data not shown). The premature stop codon caused by T618* was localised at the end of domain II, leading to an IAA9 protein devoid of domain III and IV (Fig. 1). 
Fig. 1 ClustalW protein alignment of the IAA9 wildtype (IAA9-WT) and three mutant proteins (iaa9-274, iaa9-512 and iaa9-618) identified by TILLING screenings. The IAA9 amino acid sequence of the natural mutant entire AC (iaa9eAC), having a single-base deletion at the nucleotide position 626 of the IAA9 mRNA (Zhang et al. 2007), has also been included in the comparison. The amino acid changes are boxed, while the conserved functional domains of the IAA9 protein are highlighted in grey
MSPPLLGVGEEEGQSNVTLLASSTSLGSICIKGSALKERNYMGLSDCSSVDSCNISTSSE 60 MSPPLLGVGEEEGOSNVTLLASSTSLGSICIKGSALKERNYMGLSDCSSVDSCNISTSSE 60 MSPPLLGVGEEEGQSNVTLLASSTSLGSICIKGSALKERNYMGLSDCSSVDSCNISTSSE 60 MSPPLLGVGEEEGQSNVTLLASSTSLGS ICIKGSALKERNYMGLSDCSSVDSCNISTSSE 60 MSPPLLGVGEEEGQSNVTLLASSTSLGSICIKGSALKERNYMGLSDCSSVDSCNISTSSE 60

DNNGCGLNLKATELRLGLPGSQSPERGEETCPVISTKVDEKLLFPLHPSKDTAFSVSQKT 120 DNNGCGLNLKATELRLGLPGSQSPERGEETCSVISTKVDEKLLFPLHPSKDTAFSVSQKT 120 DNNGCGLNLKATELRLGLPGSQSPERGEETCPVISTKVDEKLLFPLHPSKDTAFSVSQKT 120 DNNGCGLNLKATELRLGLPGSQSPERGEETCPVISTKVDEKLLFPLHPSKDTAFSVSQKT 120 DNNGCGLNLKATELRLGLPGSQSPERGEETCPVISTKVDEKLLFPLHPSKDTAFSVSQKT 120

Domain I

VVSGNKRGFSDAMDGFSEGKFLSNSGVKAGDTKETSRVQPPKMKDANTQSTVPERPSAVN 180 VVSGNKRGFSDAMDGFSEGKELSNSGVKAGDTKETSRVQPPKMKDANTQSTVPERPSAVN 180 VVSGNKRGFSDAMDGFSEGKFLSNSGVKAGDTKETSRVQPPKMKDANTQSIVPERPSAVN 180 VVSGNKRGFSDAMDGFSEGKFLSNSGVKAGDTKETSRVQPPKMKDANTQSTVPERPSAVN 180 VVSGNKRGFSDAMDGFSEGKFLSNSGVKAGDTKETSRVQPPKMKDANTQSTVPERPSAVN 180

DASNRAGSGAPATKAQVVGWPPIRSFRKNTLASASKNNEEVDGKAGSPALFIKVSMDGAP 240 DASNRAGSGAPATKAQVVGWPPIRSFRKNTLASASKNNEEVDGKAGSPALFIKVSMDGAP 240 DASNRAGSGAPATKAQVVGWPPIRSFRKNTLASASKNNEEVDGKAGSPALFIKVSMDGAP 240

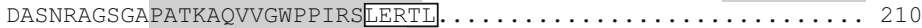

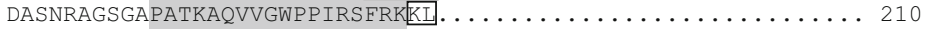

Domain II

YLRKVDLRTCSAYQELSSALEKMFSCFTIGQYGSHGAPGKDMLSESKLKDLLHGSEYVLT 300 YLRKVDLRTCSAYOELSSALEKMFSCFTIGQYGSHGAPGKDMLSESKLKDLLHGSEYVLT 300 YLRKVDLRTCSAYQELSSALEKMF SCFTIGQYGSHGAPGKDMLSESKLKDLLHGSEYVLT 300

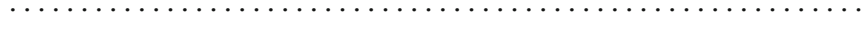

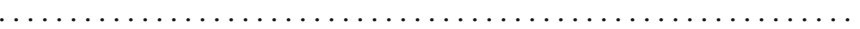

Domain III

YEDKDGDWMLVGDVPWEMFIDTCKRLRIMKGSDAIGLAPRAMEKCRSRN 349 YEDKDGDWMLVGDVPWEMFIDTCKRLRIMKGSDAIGLAPRAMEKCRSRN 349 YEDKDGDWMLVGDVPWEMFIDTCKRLRIMKGSDAIGLAPRAMEKCRSRN 349

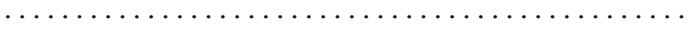

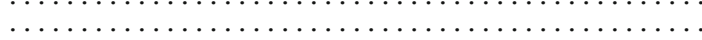

Impact of the three mutations on IAA9 mRNA steady state levels and the functionality of the IAA9 protein

Since auxin signalling is characterised by high selfregulating dynamics, we set out to measure the expression of IAA9 in leaves from the WT and the three mutants. The two missense mutations showed a transcription of the IAA9 gene that was not different from that of the WT; conversely, the iaa9-618 leaves showed a more than fourfold reduction in IAA9 transcript levels (Fig. 2a). The association of these low IAA9 mRNA levels with the homozygous state of the mutation was confirmed by the WT-like gene expression levels of siblings homozygous for the WT allele or heterozygous for T618* (Fig. 2a). In addition, the reduction in IAA9 transcripts in the iaa9-618 mutant was detected in ovaries at the fruit set stage, where the mRNA levels of the gene were barely $10 \%$ of those found in WT organs (not shown).

To investigate the impact of the mutations on the ability of the corresponding Aux/IAA proteins to in vivo regulate the activity of the synthetic DR5 auxin-responsive promoter, we carried out transient expression experiments using BY-2 protoplasts. DR5driven GFP expression was enhanced up to 25-fold by auxin treatment, and the presence of WT IAA9 proteins strongly repressed this auxin-induced activity of the DR5 promoter ( $83 \%$ repression; Fig. 2b). The iaa9-274 and iaa9-512 mutant forms of the protein retained the same repression activity as the WT protein. Confirming the sequence-based hypothesis 

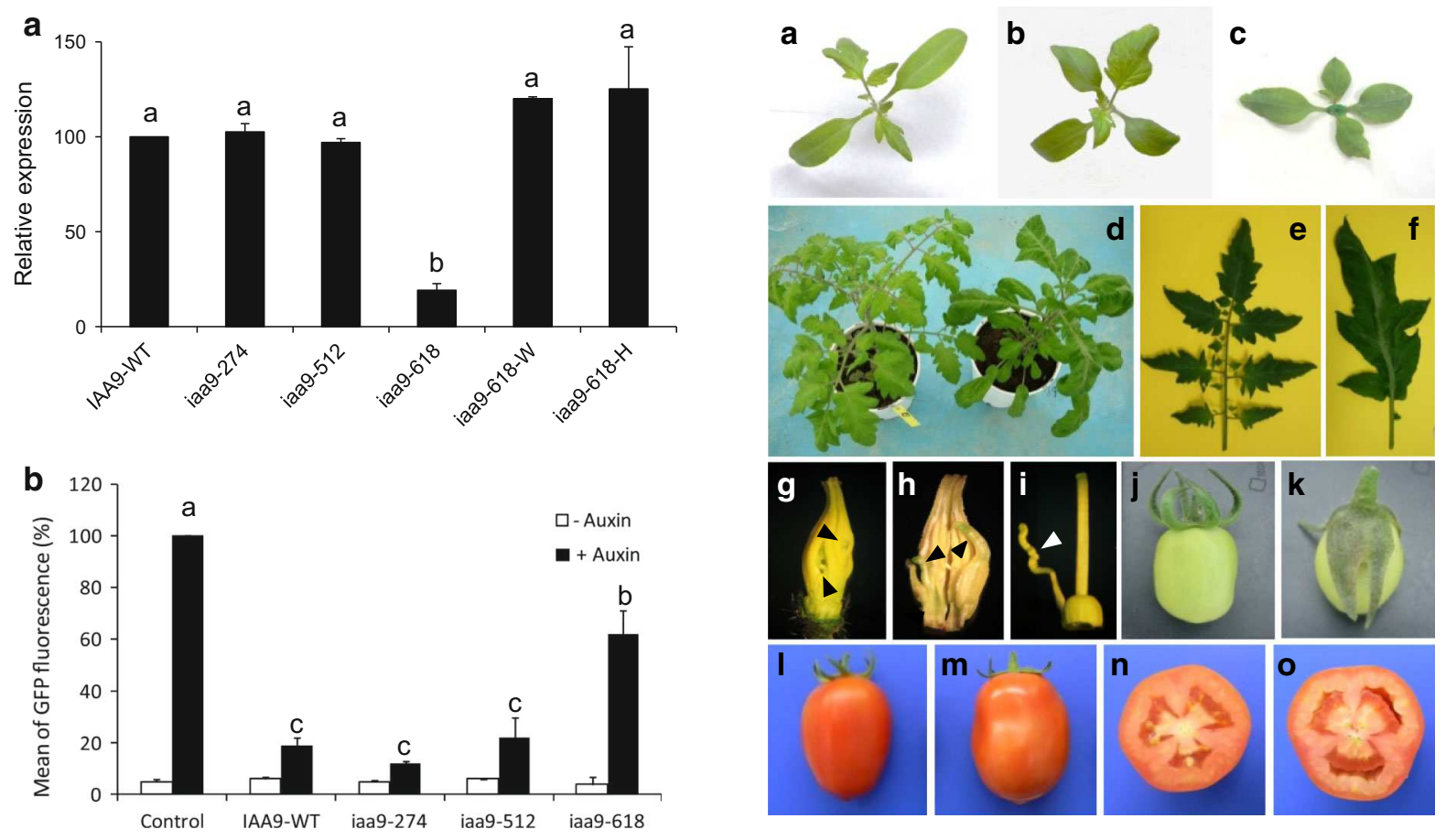

Fig. 2 Transcript levels of IAA9 gene and transcriptional repression activity of wild-type and mutated IAA9 proteins. a Transcript levels of IAA9 measured by qRT-PCR in young leaves of wild-type plants (IAA9-WT), plants homozygous for the three IAA9 mutations (iaa9-274, iaa9-512 and iaa9-618) and siblings homozygous for the WT allele (iaa9-618-W) and heterozygous for T618* (iaa9-618-H). b Activity of the DR5 promoter measured in the presence of the empty effector vector used as a control (Control), vector containing the wild-type IAA9 allele (IAA9-WT) or the three IAA9 mutant alleles (iaa9274, iaa9-512 and iaa9-618) without (white bars) or with treatment with $50 \mu \mathrm{M}$ auxin (black bars). In both histograms, bars represent the mean \pm SEM of independent experiments $(n=3)$ expressed as a percentage of the mean WT or control value. Means indicated by the same lowercase letter are not statistically different at $P \leq 0.001$ according to Tukey's HSD test carried out on raw data

of IAA9 loss-of-function, the truncated iaa9-618 form lost a significant amount of its capacity to repress DR5-driven GFP expression (Fig. 2b).

Phenotyping of the iaa9-618 mutant line

In addition to the targeted mutations, EMS-mutated plants carry a large number of background mutations. To help confirm that the observed phenotype was due to the targeted mutations, we carried out a first backcross to the WT to halve the genetic load of the mutagenised lines. Moreover, in the $\mathrm{BC}_{1} \mathrm{~F}_{2}$ segregant population, we examined plants homozygous for the

Fig. 3 Vegetative and reproductive phenotypes of the iaa9-618 mutant line compared with the Red Setter cultivar (WT). a WT seedling and b, c iaa9-618 mutant seedlings showing cotyledonary defects. d WT (left) and iaa9-618 (right) six-week-old plants. e, f Representative leaf morphology in the WT and iaa9618 mutant, respectively. g-i Details of carpelloid structures (arrowheads) in the anther cones of iaa9-618 flowers. j WT and k iaa9-618 developing fruits 3 weeks post-anthesis. I WT and m iaa9-618 whole mature fruits and $\mathbf{n}, \mathbf{o}$ in cross section, respectively

WT allele and heterozygotes for the expected phenotypes in parallel with homozygous mutant plants. Comparisons between WT and mutant lines were finally carried out using the Red Setter cultivar as a control in all experiments.

As suggested by the functional characterisation, the two missense mutant lines showed no clear phenotypic difference compared with the WT for the traits expected as a consequence of IAA9 silencing (Wang et al. 2005). Therefore, we carried out a thorough phenotypic characterisation only for the iaa9-618 line. With respect to the phenotypic effects described below, the IAA9 $\mathrm{T}_{618} *$ mutation behaved as a monogenic recessive.

\section{Vegetative development}

Aberrations in cotyledon morphology were never found in the WT (Fig. 3a) or in $\mathrm{BC}_{1} \mathrm{~F}_{2}$ siblings 
homozygous for the WT allele. Conversely, these aberrations were evident in plants homozygous for the IAA9 T618* mutation, with an overall penetrance of $47.1 \%$ (Table 1). Cotyledon aberrations consisted of "leafy" cotyledons and tricots (Fig. 3b). Plants carrying the T618* mutation showed additional cotyledonary defects, such as a wider lamina (Fig. 3c), often with varying degrees of distortion (not shown).

Compared to the WT, the iaa9-618 mutant line exhibited leaves with a significant reduction in compoundness and a minimally lobed leaf margin (Fig. 3d-f; Table 1). The association of the leaf phenotype with the lesion in the IAA9 gene in this line was confirmed by the phenotype of siblings heterozygous for T618* or homozygous for the WT allele, which exhibited leaf compoundness comparable to that of the WT (not shown).

Although the pattern of axillary shoot growth was variable in the analysed plants, iaa9-618 mutants showed significantly longer axillary shoots at two out of three examined nodes compared to the WT (Table 1).

Reproductive development

The iaa9-618 mutant line did not differ from the WT in terms of flowering time, number of flowers per inflorescence or inflorescence type, maintaining the simple inflorescence typical of Red Setter (not shown). The floral organ number was also not different in the mutant. The most relevant difference in floral morphology was a homeotic transformation of stamens, which showed carpelloid features; this trait was $41 \%$ penetrant in the iaa9-618 line (Fig. 3g-i; Table 1). Moreover, the mutant flowers exhibited fusion of sepals at the insertion in the receptacle, a phenotype that was remarkably evident during early fruit growth (Fig. 3k).

We first evaluated the parthenocarpic capacity of the mutant plants by measuring the fresh ovary weight at anthesis and the capability of emasculated flowers to develop in the absence of fertilisation. As happens in other parthenocarpic systems (Mapelli et al. 1978; Fos and Nuez 1991; Carmi et al. 2003), the ovary weight at anthesis was significantly higher in the iaa9-618 mutant line than in the WT (Table 1). The weight of fruitlets that developed after emasculation was also higher in the mutant, although this value was highly variable because only approximately $40 \%$ of the emasculated flowers showed parthenocarpic development of unpollinated ovaries (not shown).

\section{Production data}

For plants grown in a protected environment, the fruit set was higher in the iaa9-618 line than in the WT (Table 2). Compared to the WT (Fig. 31), iaa9-618 fruits (Fig. $3 \mathrm{~m}$ ) had a higher mean weight, a more elongated shape and a similar potential yield (Table 2). As expected, the frequency of seedless fruits was very low in the WT (Fig. 3n) and high in the mutant (Fig. 3o). In addition, the seeded mutant fruits carried, on average, approximately half the number of seeds present in WT fruits under the same growth conditions (Table 2). The internal fruit structure was similar in WT and mutant fruits; the increase in

Table 1 Vegetative and reproductive traits in the cultivar Red Setter (WT) and the iaa9-618 mutant line

\begin{tabular}{llrrr}
\hline Trait category & Trait & WT & iaa9-618 & $P$ value $^{\mathrm{a}}$ \\
\hline Vegetative traits & Seedlings with aberrant cotyledon morphology $(\%)$ & 0 & 47.1 & $\leq 0.01$ \\
& No. of simple leaflets & 9.2 & 1.5 & $\leq 0.01$ \\
& No. of compound leaflets & 5.3 & 0 & $\leq 0.01$ \\
& Length of axillary shoot at 2nd node $(\mathrm{cm})$ & 11.5 & 25.9 & $\leq 0.01$ \\
& Length of axillary shoot at 4th node $(\mathrm{cm})$ & 9.5 & 20.3 & $\leq 0.01$ \\
& Length of axillary shoot at last node $(\mathrm{cm})$ & 16.0 & 21.9 & 0.06 \\
Reproductive traits & 6.3 & 41.0 & $\leq 0.01$ \\
& Carpelloid stamens (\%) & 5.9 & 7.5 & $\leq 0.01$ \\
& Ovary weight at anthesis (mg) & 8.5 & 53.2 & 0.03 \\
\hline
\end{tabular}

\footnotetext{
a According to Student's $t$ test or, for estimates made as percentages, to homogeneity $\chi^{2}$ analysis

${ }^{\mathrm{b}}$ DAE, $\mathrm{d}$ after emasculation
} 
Table 2 Productive traits in the cultivar Red Setter (WT) and the $\mathrm{BC}_{1} \mathrm{~F}_{3}$ iaa9-618 mutant plants grown under greenhouse and openfield conditions

\begin{tabular}{|c|c|c|c|c|c|c|}
\hline \multirow[t]{2}{*}{ Trait } & \multicolumn{3}{|c|}{ Greenhouse } & \multicolumn{3}{|l|}{ Field } \\
\hline & WT & iaa9-618 & $P$ value & WT & iaa9-618 & $P$ value $^{\mathrm{a}}$ \\
\hline Fruit set $(\%)$ & 44.6 & 55.4 & 0.05 & $-{ }^{\mathrm{b}}$ & - & - \\
\hline Fruit weight $(\mathrm{g})^{\mathrm{c}}$ & 58.5 & 72.6 & 0.02 & 65.5 & 76.6 & $\leq 0.01$ \\
\hline Fruit shape index & 1.25 & 1.42 & $\leq 0.01$ & 1.21 & 1.20 & 0.21 \\
\hline Potential yield $\left(\mathrm{g}\right.$ plant ${ }^{-1}$ ) & $742^{\mathrm{d}}$ & $857^{\mathrm{d}}$ & 0.34 & $3661^{\mathrm{e}}$ & $1907^{\mathrm{e}}$ & 0.02 \\
\hline Seedless fruits $(\%)$ & 3.5 & 68.1 & $\leq 0.01$ & 0 & 93.3 & $\leq 0.01$ \\
\hline No. of seeds per fruit & 20.5 & $11.8^{\mathrm{f}}$ & 0.03 & 59.3 & $19.0^{\mathrm{f}}$ & $\leq 0.01$ \\
\hline Brix value & 4.23 & 5.08 & $\leq 0.01$ & 4.02 & 4.84 & $\leq 0.01$ \\
\hline Firmness & 2.53 & 2.37 & 0.27 & 2.26 & 2.38 & 0.28 \\
\hline
\end{tabular}

\footnotetext{
a According to Student's $t$ test or, for estimates made as percentages, to homogeneity $\chi^{2}$ analysis

${ }^{\mathrm{b}}$ Not determined

${ }^{\mathrm{c}}$ Calculated on about 120 and 30 fruits harvested from plants grown in greenhouse and open-field conditions respectively

${ }^{\mathrm{d}}$ Calculated for the first four trusses

${ }^{\mathrm{e}}$ Calculated for the whole plant at maturity

${ }^{\mathrm{f}}$ Calculated only for fruits with seeds
}

pericarp thickness described by Saito et al. (2011) in iaa9 mutants in the Micro-Tom background was not observed in iaa9-618. Finally, iaa9-618 fruits showed a significantly higher brix value and similar firmness compared to seeded fruits produced by the WT (Table 2).

To determine whether the quality traits of the mutant fruits were related to their seedless or seeded condition, we measured the fruit weight and shape, brix value and seedlessness on a single fruit basis in a sub-sample of fruits. For all traits, seedless and seeded iaa9-618 fruits did not show significantly different values (Table $\mathrm{S} 1$ ).

We also compared the productive performance of the iaa9-618 line to that of the WT in the open field. In the field, the fruit weight and brix value were higher in the mutant than in the WT, but the fruit shape index was similar between the two genotypes (Table 2). The mutant line exhibited a high degree of parthenocarpy (approximately $93 \%$ seedless fruits and one-third the number of seeds in mutant seeded fruits compared to WT), although the potential yield under open-field conditions was lower in the iaa9-618 plants (Table 2). As observed under protected cultivation, the two genotypes produced fruits with comparable firmness (Table 2).

The fertility of the iaa9-618 mutant plants was indirectly assessed in controlled crosses. When used as the seed parent and pollinated with WT pollen, iaa9618 plants produced approximately 60 seeds per fruit, whereas WT plants pollinated with iaa9-618 pollen produced approximately 50 seeds per fruit. These values, which are comparable to the values for seed production in the WT under open (Table 2) or hand pollination in the field (not shown), indicate that the iaa9-618 plants did not exhibit a major decline in fertility.

The capacity for seed production in the mutant line was influenced by inflorescence order; more than $80 \%$ of the seeds obtained from iaa9-618 plants in the $\mathrm{BC}_{1} \mathrm{~F}_{3}$ generation under greenhouse cultivation were produced by trusses of order higher than four, whereas fruits of the first four trusses were either seedless or contained very few seeds (not shown).

\section{Discussion}

To identify novel sources of parthenocarpy to be used for breeding, we harnessed mutant alleles of the IAA9 gene by TILLING using a platform developed in a processing tomato genetic background. It was previously reported that silencing of this gene specifically induces parthenocarpy in tomato (Wang et al. 2005; Saito et al. 2011). The screening of 5,200 $\mathrm{M}_{3}$ families yielded three mutant tomato lines with genetic lesions 
in the IAA9 coding sequence. Of these, two carried a point mutation leading to amino acid substitutions and the third carried a single-base deletion leading to a frame shift and a premature stop codon. This stop codon was coincident with that predicted in the $e$ mutant (Zhang et al. 2007; Fig. 1).

The iaa9-618 mutation affects both the transcript level of the gene and the function of the protein

In accordance with the predicted tolerability of the relative mutations, the iaa9-274 and iaa9-512 mutant lines were not different from the WT in terms of gene transcription or the capacity of the respective proteins to repress the activation of the auxin-inducible DR5 promoter. Conversely, plants carrying the frame-shift mutation showed remarkable phenotypes when analysed at the transcriptional or protein activity level. Compared with the WT, the missense mutant lines and siblings heterozygous for the IAA9 T618* mutation or homozygous for the WT allele, iaa9-618 mutants showed a strong reduction in the transcription level of the IAA9 gene. Accordingly, low levels of IAA9 expression were also found in the $e$ mutant (Wang et al. 2005; Zhang et al. 2007). This reduction was even more dramatic in ovaries, suggesting the occurrence of feed-forward regulation or nonsense-mediated mRNA decay (NMD) mechanisms. NMD functions as a quality control mechanism to eliminate abnormal transcripts (Lejeune and Maquat 2005).

Moreover, analysis of protein functionality showed that the truncated protein lost approximately $68 \%$ of its repressing ability. Thus, even if the iaa9-618 protein lacks functional domains III and IV, part of its activity is maintained in the absence of dimerisation or alternatively, the protein can still form functional complexes in its truncated form.

Taken together, the data indicate that among the three mutated versions of the IAA9 protein, only the truncated form resulted in a partial loss of IAA9 function due to a combination of reduced gene transcription and reduced protein functionality.

The IAA9 T618* mutation causes IAA-related vegetative and reproductive defects

Observation of plants carrying the missense mutations in the homozygous state did not reveal the phenotypes expected from the analysis of AS-IAA9 tomato plants
(Wang et al. 2005). Conversely, characterisation of plants carrying the frame-shift mutation T618* revealed severe phenotypes, which were in agreement with the expected phenotypes.

Vegetative phenotypes such as those affecting cotyledon number and morphology were previously observed in AS-IAA9 (Wang et al. 2005) and in other tomato parthenocarpic backgrounds such as TPRPF1::rolB (Carmi et al. 2003) and the pat mutant (Olimpieri et al. 2007). Thus, regulatory elements controlling ovary growth also play a role in the control of cotyledon patterning during embryogenesis. Other vegetative phenotypes in agreement with IAA9 silencing (Wang et al. 2005; Zhang et al. 2007; Berger et al. 2009; Saito et al. 2011) were observed in the iaa9-618 line, such as defects in apical dominance and a reduction in leaf compoundness. These phenotypes support the important role played by auxin in patterning leaf morphogenesis and dissection (Molesini et al. 2009; Ren et al. 2011).

In parallel with other IAA9 knock-out genotypes (Wang et al. 2005, 2009; Saito et al. 2011), iaa9-618 mutant plants showed a strong tendency to develop parthenocarpic fruits. Ovaries of mutated plants at anthesis weighed more than WT ovaries and showed the capacity to develop in emasculated, unpollinated flowers. As the iaa9-618 and $e$ mutations produce very similar truncated proteins, it will be interesting to investigate the reproductive behaviour of the $e$ mutant.

Notably, iaa9-618 flowers exhibited carpelloid stamens, a phenotype not described in AS-IAA9 (Wang et al. 2009) or IAA9 mutants (Zhang et al. 2007; Saito et al. 2011). This novel phenotype cosegregated with the IAA9 T618* mutation. Although it cannot be excluded that the carpelloidy of stamens was driven by a linked mutation, several lines of evidence suggest that this phenotype is a pleiotropic effect of IAA9 loss-of-function. Carpelloidy in iaa9-618 parallels the association between parthenocarpy and stamen defects found in parthenocarpic (Mazzucato et al. 1998) and male sterile (Gomez et al. 1999; Olimpieri and Mazzucato 2008) tomato mutants and in plants downregulated for stamen identity genes (Lifschitz et al. 1993; Ampomah-Dwamena et al. 2002; Geuten and Irish 2010). A similar, partially penetrant phenotype was also observed in the flowers of the tomato pat-2 mutant (A. Mazzucato and F. Ruiu, unpublished data). Accordingly, the expression of floral identity genes is modulated by pollination in 
wild-type flowers, and this modulation is altered in flowers of parthenocarpic mutants (Mazzucato et al. 2008) and of plants engineered for parthenocarpy (Wang et al. 2009). DEFICIENS (DEF), a class B MADS-box gene that is responsible for the identity of the second and third floral whorl (Weigel and Meyerowitz 1994), is also expressed and modulated in the ovary at fruit set (Mazzucato et al. 2008; Vriezen et al. 2008). The expression of $D E F$ is also significantly lower in iaa9-618 ovaries than in WT ovaries at the same developmental stage (A. Mazzucato and F. Ruiu, unpublished data). Thus, $D E F$ shows additional functions in the fourth whorl, taking part in mechanisms mediating the ovary-to-fruit transition. Accordingly, downregulation of genes orthologue to GLOBOSA $(G L O)$ that encodes the functional partner of $D E F$, is correlated with the post-pollination development of the ovary in Phalaenopsis (Tsai et al. 2005) and with parthenocarpy in apple (Yao et al. 2001). In this context, carpelloidy in iaa9-618 stamens may be related to a deregulation of $D E F$, which in turn is also involved in the parthenocarpic behaviour of the ovary.

The iaa9-618 line may be useful for breeding parthenocarpic tomatoes

Genetic parthenocarpy represents an interesting breeding goal because it offers the opportunity for higher yields under conditions that are suboptimal for pollination, as well as the opportunity for higher fruit quality in terms of soluble solids content. However, parthenocarpic mutants have not been widely adopted in tomato breeding because they often exhibit fruit defects (smaller size, misshapen aspect and lower firmness) or difficulties in seed production (Table S2). Since known mutations for parthenocarpy in tomato are recessive, they must be introgressed in both parental lines in hybrid breeding; this requires simple genetic control of parthenocarpy and mapping information for assisted selection. None of the previously described sources of parthenocarpy in tomato fulfil all of these requirements.

Plants carrying the $\mathrm{T} 618 *$ frame-shift mutation described here showed fruits the same size as, or larger than, those of the WT, with normal shapes, similar firmness and higher brix values. As reported in other parthenocarpic systems (Santangelo et al. 1990; Carmi et al. 2003), the correlation between fruit weight and seed content found in wild-type tomatoes was not observed in fruits of the iaa9-618 line (Fig. S2). Interestingly, characteristic traits distinguishing iaa9618 from WT fruits (higher weight and brix values and a more elongated shape) were similar in seeded and seedless iaa9-618 fruits.

Few reports have compared the yield potential of parthenocarpic lines to their corresponding, near isogenic, non-parthenocarpic counterparts. Under standard growth conditions, parthenocarpy is thought to enable yields similar to those of wild-type tomatoes, whereas it represents an advantage under conditions limiting pollen production and fertilisation. It is generally recognised that the maximum expressivity of parthenocarpy occurs under environmental conditions with low night temperatures and high light intensity (Santangelo et al. 1990; George et al. 1984). The greenhouse cultivation performed in the current experiment represents a pollination-limiting environment, at least for the night temperature, which averaged below $15^{\circ} \mathrm{C}$, a lower limit for good pollen production and pollination in tomato (George et al. 1984). Indeed, the unitary seed production in WT fruits was one-third that recorded under open-field conditions or in the greenhouse after hand pollination. In controlled environments, fruit set is also hampered by a reduction in wind and insects, which shake the flowers, greatly facilitating pollination and increasing fruit setting in tomato. Under these conditions, the iaa9-618 line set $25 \%$ more fruits and was estimated to have $15 \%$ higher potential productivity than the WT, although the latter difference was not significant. Finally, the data show that seedlessness in iaa9-618 is essentially due to the precocious growth of the ovary. Mutant flowers are fertile and seeds may easily be produced by hand pollination or by open pollination at higher plant trusses. Seed increase could be further facilitated if more permissive conditions for seed production are identified, as was reported for various pat tomato mutants (Philouze et al. 1988; Mazzucato et al. 1998; Fos et al. 2001).

\section{Conclusion}

The data presented here describe T618*, a novel IAA9 allele that may contribute to our understanding of fruit set and parthenocarpy mechanisms and may facilitate the use of genetic parthenocarpy in tomato breeding. As iaa9-618 plants set more and larger fruits than the 
WT, with higher brix values and comparable firmness, they present the potential for improving yields under pollination-limiting conditions and for breaking the negative correlation between seedlessness and firmness reported in other parthenocarpic mutants (Gorguet et al. 2005). The iaa9-618 mutant condition is easily selectable by leaf morphology or molecular analysis. In addition, the iaa9-618 mutant line did not show any major fertility problems and is thus suitable for hybrid seed production and seed increase in the parental lines. Although wider experiments, including growth under harsher growth conditions, are needed to better define the potential of using IAA9 mutations in breeding, previous (Wang et al. 2005; Saito et al. 2011) and present data suggest that this gene is a promising target for harnessing parthenocarpy in tomato.

Acknowledgments This work was funded by the Italian Ministry of University and Research (MIUR, ITALYCO Project, DD no 603/RIC). The authors thank Rinaldo Botondi for help with the measurement of firmness, Pietro Mosconi and Luigi Selleri for help with mutant phenotyping and Loredana Lanzillotti for hosting the field trial at Azienda Gaudiano-ALSIA in Lavello (Pz).

\section{References}

Abel S, Theologis A (1994) Transient transformation of Arabidopsis leaf protoplasts: a versatile experimental system to study gene expression. Plant J 5:421-427

Ampomah-Dwamena C, Morris B, Sutherland P, Veit B, Yao J-L (2002) Down-regulation of TM29, a tomato SEPALLATA homolog, causes parthenocarpic fruit development and floral reversion. Plant Physiol 130:605-617

Audran-Delalande C, Bassa C, Mila I, Regad F, Zouine M, Bouzayen M (2012) Genome-wide identification, functional analysis and expression profiling of $A u x / I A A$ gene family in tomato. Plant Cell Physiol 53:659-672

Bassa C, Mila I, Bouzayen M, Audran-Delalande C (2012) Phenotypes associated with down-regulation of Sl-IAA27 support functional diversity among Aux/IAA family members in the tomato. Plant Cell Physiol 53:1583-1595

Berger Y, Harpaz-Saad S, Brand A, Melnik H, Sirding N, Alvarez JP, Zinder M, Samach A, Eshed Y, Ori N (2009) The NAC-domain transcription factor GOBLET specifies leaflet boundaries in compound tomato leaves. Development 136:823-832

Bianchi A, Soressi GP (1969) Mutanti di pomodoro artificialmente indotti suscettibili di utilizzazione nel miglioramento genetico. Sementi Elette 15(3):2-6

Carmi N, Salts Y, Dedicova B, Shabtai S, Barg R (2003) Induction of parthenocarpy in tomato via specific expression of the rolB gene in the ovary. Planta 217:726-735
Chaabouni S, Jones B, Delalande C, Wang H, Li Z, Mila I, Frasse P, Latché A, Pech JC, Bouzayen M (2009) Sl-IAA3, a tomato Aux/IAA at the crossroads of auxin and ethylene signalling involved in differential growth. J Exp Bot 60:1349-1362

Dalmais M, Schmidt J, Le Signor C, Moussy F, Burstin J, Savois V, Aubert G, Brunaud V, de Oliveira Y, Guichard C, Thompson R, Bendahmane A (2008) UTILLdb, a Pisum sativum in silico forward and reverse genetics tool. Genome Biol 9:R43

De Jong M, Wolters-Arts M, Feron R, Mariani C, Vriezen WH (2009) The Solanum lycopersicum auxin response factor 7 (SlARF7) regulates auxin signaling during tomato fruit set and development. Plant J 57:160-170

Deng W, Yang Y, Ren Z, Delalande C, Mila I, Wang X, Song H, $\mathrm{Hu}$ Y, Bouzayen M, Li Z (2012) The tomato SIIAA15 is involved in trichome formation and axillary shoot development. New Phytol 194:379-390

Dharmasiri N, Dharmasiri S, Estelle M (2005) The F-box protein TIR1 is an auxin receptor. Nature 435:441-445

Doyle JJ, Doyle JL (1987) A rapid DNA isolation procedure for small quantities of fresh leaf tissue. Phytochem Bull 19:11-15

Expósito-Rodríguez M, Borges AA, Borges-Pérez A, Pérez JA (2008) Selection of internal control genes for quantitative real-time RT-PCR studies during tomato development process. BMC Plant Biol 8:131

Falavigna A, Badino M, Soressi GP (1978) Possibilità di impiego del carattere di partenocarpia pat nel miglioramento genetico del pomodoro da industria. Genetica Agraria 32:159-160

Fos M, Nuez F (1991) Efecto de la partenocarpia sobre el desarrollo de ovarios en tomate. Actas Horticultura 8:63-71

Fos M, Nuez F, Garcia-Martinez J (2000) The gene pat-2, which induces natural parthenocarpy, alters the gibberellin content in unpollinated ovaries. Plant Physiol 122:471-479

Fos M, Proano K, Nuez F, Garcia-Martinez J (2001) Role of gibberellins in parthenocarpic fruit development induced by the genetic system pat-3/pat-4 in tomato. Physiol Plant 111:545-550

George WL, Scott J, Splittstoesser W (1984) Parthenocarpy in tomato. Hort Rev 6:65-84

Geuten K, Irish V (2010) Hidden variability of floral homeotic B genes in Solanaceae provides a molecular basis for the evolution of novel functions. Plant Cell 22:2562-2578

Goetz M, Hooper LC, Johnson SD, Rodrigues JCM, VivianSmith A, Koltunow AM (2007) Expression of aberrant forms of AUXIN RESPONSE FACTOR8 stimulates parthenocarpy in Arabidopsis and tomato. Plant Physiol 145:351-366

Gomez P, Jamilena M, Capel J, Zurita S, Angosto T (1999) Stamenless, a tomato mutant with homeotic conversions in petals and stamens. Planta 209:172-179

Gorguet B, van Heusden AW, Lindhout P (2005) Parthenocarpic fruit development in tomato. Plant Biol 7:131

Gray WM, Kepinski S, Rouse D, Leyser O, Estelle M (2001) Auxin regulates SCFTIR1-dependent degradation of AUX/ IAA proteins. Nature 414:271-276

Guilfoyle TJ (1998) Aux/IAA proteins and auxin signal transduction. Trends Plant Sci 3:205-207 
Kim J, Harter K, Theologis A (1997) Protein-protein interactions among the Aux/IAA proteins. Proc Natl Acad Sci USA 94:11786-11791

Leclercq J, Ranty B, Sanchez-Ballesta MT, Li Z, Jones B, Jauneau A, Pech J-C, Latché A, Ranjeva R, Bouzayen M (2005) Molecular and biochemical characterization of LeCRK1, a ripening associated tomato CDPK-related kinase. J Exp Bot 56:25-35

Lejeune F, Maquat LE (2005) Mechanistic links between nonsense-mediated mRNA decay and pre-mRNA splicing in mammalian cells. Curr Opin Cell Biol 17:309-315

Lifschitz E, Brodai L, Hareven D, Hurwitz C, Prihadash A, Pnueli L, Samach A, Zamir D (1993) Molecular mapping of flower development in tomato. In: Yoder Y, Lancaster PA (eds) Molecular biology of tomato. Technomic Publishing, Lancaster, PA, pp 175-184

Lin S, George W, Splittstoesser W (1984) Expression and inheritance of parthenocarpy in 'Severianin' tomato. J Hered 75:62-66

Mapelli S, Frova C, Torti G, Soressi GP (1978) Relationship between set, development and activities of growth regulators in tomato fruits. Plant Cell Physiol 19:1281-1288

Martí C, Orzáez D, Ellul P, Moreno V, Carbonell J, Granell A (2007) Silencing of DELLA induces facultative parthenocarpy in tomato fruits. Plant J 52:865-876

Mazzucato A, Taddei AR, Soressi GP (1998) The parthenocarpic fruit (pat) mutant of tomato (Lycopersicon esculentum Mill.) sets seedless fruits and has aberrant anther and ovule development. Development 125:107-114

Mazzucato A, Olimpieri I, Ciampolini F, Cresti M, Soressi GP (2003) A defective pollen-pistil interaction contributes to hamper seed set in the parthenocarpic fruit tomato mutant. Sex Plant Reprod 16:157-164

Mazzucato A, Olimpieri I, Siligato F, Picarella ME, Soressi GP (2008) Characterization of genes controlling stamen identity and development in a parthenocarpic tomato mutant indicates a role for the DEFICIENS ortholog in the control of fruit set. Physiol Plant 132:526-537

McCallum CM, Comai L, Greene EA, Henikoff S (2000) Targeting induced local lesions IN genomes (TILLING) for plant functional genomics. Plant Physiol 123:439-442

Minoia S, Petrozza A, D’ Onofrio O, Piron F, Mosca G, Sozio G, Cellini F, Bendahmane A, Carriero F (2010) A new mutant genetic resource for tomato crop improvement by TILLING technology. BMC Res Notes 3:69

Molesini B, Pandolfini T, Rotino GL, Dani V, Spena A (2009) Aucsia gene silencing causes parthenocarpic fruit development in tomato. Plant Physiol 149:534-548

Ng PC, Henikoff S (2003) SIFT: predicting amino acid changes that affect protein function. Nucl Acid Res 31:3812-3814

Nuez F, Costa J, Cuartero J (1986) Genetics of the parthenocarpy for tomato varieties 'Sub-Arctic Plenty' 75/59' and 'Severianin'. Z Pflanzenzuchtg 96:200-206

Olimpieri I, Mazzucato A (2008) Phenotypic and genetic characterization of the pistillate mutation in tomato. Theor Appl Genet 118:151-163

Olimpieri I, Siligato F, Caccia R, Soressi GP, Mariotti L, Ceccarelli N, Mazzucato A (2007) Tomato fruit set driven by pollination or by the parthenocarpic fruit allele are mediated by transcriptionally regulated gibberellin biosynthesis. Planta 226:877-888
Ottenschlager I, Wolff P, Wolverton C, Bhalerao RP, Sandberg G et al (2003) Gravity regulated differential auxin transport from columella to lateral root cap cells. Proc Natl Acad Sci USA 100:2987-2991

Overvoorde PJ, Okushima Y, Alonso JM, Chan A, Chang C, Ecker JR, Hughes B, Liu A, Onodera C, Quach H, Smith A, $\mathrm{Yu} \mathrm{G}$, Theologis A (2005) Functional genomic analysis of the AUXIN/INDOLE-3-ACETIC ACID gene family members in Arabidopsis thaliana. Plant Cell 17:3282-3300

Philouze J, Buret M, Duprat F, Nicolas-Grotte M, Nicolas J (1988) Caractéristiques agronomiques et physico-chimiques de lignées de tomates isogéniques, sauf pour le gène pat-2 de parthénocarpie, dans trois types variétaux, en culture de printemps, sous serre plastique très peu chauffée. Agronomie 8:817-828

Reed J (2001) Roles and activities of Aux/IAA proteins in arabidopsis. Trends Plant Sci 6:420-425

Ren Z, Li Z, Miao Q, Yang Y, Deng W et al (2011) The auxin receptor homologue in Solanum lycopersicum stimulates tomato fruit set and leaf morphogenesis. J Exp Bot 62:2815-2826

Ruan YL, Patrick JW, Bouzayen M, Osorio S, Fernie AR (2012) Molecular regulation of seed and fruit set. Trends Plant Science 17:656-665

Saito T, Ariizumi T, Okabe Y, Asamizu E, Hiwasa-Tanase K, Fukuda N, Mizoguchi T, Yamazaki Y, Aoki K, Ezura H (2011) TOMATOMA: a novel tomato mutant database distributing Micro-Tom mutant collections. Plant Cell Physiol 52:283-296

Santangelo E, Benedettelli S, Tomassini C, Soressi GP (1990) Comportamento in tunnel freddo delle versioni, quasi isogeniche, normale e partenocarpica di tre ibridi di pomodoro. Colture Protette 11:81-90

SAS Institute (2004) SAS language and procedure: usage, version 8.1. SAS Institute Inc, Cary, NC

Slade AJ, Fuerstenberg SI, Loeffler D, Steine MN, Facciotti D (2005) A reverse genetic, nontransgenic approach to wheat crop improvement by TILLING. Nat Biotechnol 23:75-81

Srivastava A, Handa A (2005) Hormonal regulation of tomato fruit development: a molecular perspective. J Plant Growth Regul 24:67-82

Tan X, Calderon-Villalobos LIA, Sharon M, Zheng C, Robinson CV, Estelle M, Zheng N (2007) Mechanism of auxin perception by the TIR 1 ubiquitin ligase. Nature 446:640-645

Thompson JD, Higgins DG, Gibson TJ (1994) CLUSTALW: improving the sensitivity of progressive multiple sequence alignment through sequence weighting, position-specific gap penalties and weight matrix choice. Nucleic Acids Res 22:4673-4680

Triques K, Sturbois B, Gallais S, Dalmais M, Chauvin S, Clepet C, Aubourg S, Rameau C, Caboche M, Bendahmane A (2007) Characterization of Arabidopsis thaliana mismatch specific endonucleases: application to mutation discovery by TILLING in pea. Plant J 51:1116-1125

Tsai W-C, Lee PF, Chen HI, Hsiao Y-Y, Wei W-J, Pan Z-J, Chuang M-H, Kuoh C-S, Chen W-H, Chen H-H (2005) PeMADS6, a GLOBOSA/PISTILLATA-like gene in Phalaenopsis equestris involved in petaloid formation, and correlated with flower longevity and ovary development. Plant Cell Physiol 46:1125-1139 
Ulmasov T, Murfett J, Hagen G, Guilfoyle T (1997) Aux/IAA proteins repress expression of reporter genes containing natural and highly active synthetic auxin response elements. Plant Cell 9:1963-1971

Vriezen WH, Feron R, Maretto F, Keijman J, Mariani C (2008) Changes in tomato ovary transcriptome demonstrate complex hormonal regulation of fruit set. New Phytol 177:60-76

Wang H, Jones B, Li Z, Frasse P, Delalande C, Regad F, Chaabouni S, Latche A, Pech J-C, Bouzayen M (2005) The tomato Aux/IAA transcription factor IAA9 is involved in fruit development and leaf morphogenesis. Plant Cell 17:2676-2692

Wang H, Schauer N, Usadel B, Frasse P, Zouine M, Hernould M, Latche A, Pech J-C, Fernie AR, Bouzayen M (2009)
Regulatory features underlying pollination-dependent and -independent tomato fruit set revealed by transcript and primary metabolite profiling. Plant Cell 21:1428-1452

Weigel D, Meyerowitz E (1994) The ABCs of floral homeotic genes. Cell 78:203-209

Yao J-L, Dong Y-H, Morris B (2001) Parthenocarpic apple fruit production conferred by transposon insertion mutations in a MADS-box transcription factor. Proc Natl Acad Sci USA 98:1306-1311

Zhang J, Chen R, Xiao J, Qian C, Wang T, Li H, Ouyang B, Ye Z (2007) A single-base deletion mutation in SIIAA9 gene causes tomato (Solanum lycopersicum) entire mutant. J Plant Res 120:671-678 